\title{
Development of a Rat Sandwich-Cultured Hepatocytes Model Expressing Functional Human Organic Anion Transporting Polypeptide (OATP) 1B3: A Potential Screening Tool for Liver-Targeting Compounds
}

\author{
Taleah Farasyn ${ }^{1}$, Chao $\mathrm{Xu}^{2}$, and Wei Yue \\ ${ }^{1}$ Department of Pharmaceutical Sciences, College of Pharmacy, University of Oklahoma Health Sciences Center, Oklahoma \\ City, Oklahoma, USA; ${ }^{2}$ Department of Biostatistics and Epidemiology, College of Public Health, University of Oklahoma \\ Health Sciences Center, Oklahoma City, Oklahoma, USA
}

Corresponding author: Wei Yue, College of Pharmacy, University of Oklahoma Health Sciences Center, 1110 N. Stonewall Avenue, Suite 328, Oklahoma City, Oklahoma, 73117, USA; TEL: (405) 271-6593 Ext. 47828; Fax: (405) 271-7505; email: wei-yue@ouhsc.edu

Received, March 15, 2021; Revised, July 29, 2021; Accepted, August 2, 2021; Published, September 11, 2021

\begin{abstract}
Purpose: Organic anion transporting polypeptide (OATP) 1B3 transports many clinically important drugs, including statins, from blood into the liver. It exclusively expresses in human liver under normal physiological conditions. There is no rodent ortholog of human OATP1B3. Tissue targeting of therapeutic molecules mediated by transporters, including liver-targeting via liver-specific OATPs, is an emerging area in drug development. Sandwich-cultured primary hepatocytes $(\mathrm{SCH})$ are a well characterized in vitro model for assessment of hepatic drug uptake and biliary excretion. The current study was designed to develop a novel rat SCH model expressing human OATP1B3 to study the hepatic disposition of OATP1B3 substrates. Methods: Primary rat hepatocytes transduced with adenoviral vectors expressing FLAG-tagged OATP1B3 (Ad-OATP1B3), a control vector Ad-LacZ, or that were non-transduced were cultured in a sandwich configuration. FLAG immunoblot and immunofluorescence-staining determined expression and localization of OATP1B3. Uptake of $\left[{ }^{3} \mathrm{H}\right]$-cholecystokinin octapeptide (CCK-8), a specific OATP1B3 substrate, was determined. Taurocholate (TC) is a substrate routinely used in SCH to assess biliary excretion via bile canaliculi (BC) and is also a substrate of OATP1B3. $\left[{ }^{3} \mathrm{H}\right]-\mathrm{TC}$ accumulation in cells+BC, cells, biliary excretion index (BEI) and in vitro $\mathrm{Cl}_{\text {biliary }}$ were determined using B-CLEAR ${ }^{\circledR}$ technology. Results: OATP1B3 protein was extensively expressed and primarily localized on the plasma membrane in day 4 Ad-OATP1B3-transduced rat SCH. $\left[{ }^{3} \mathrm{H}\right]-\mathrm{CCK}-8$ accumulation in cells+BC was significantly greater $(\sim 5-13$ folds, $p<0.001)$ in day $4 \mathrm{SCH}$ with vs. without Ad-OATP1B3transduction. Expressing OATP1B3 in rat $\mathrm{SCH}$ significantly increased $\left[{ }^{3} \mathrm{H}\right]-\mathrm{TC}$ accumulation in cells $+\mathrm{BC}$ and cells, without affecting BEI and in vitro $\mathrm{Cl}_{\text {biliary. }}$ Conclusions: $\mathrm{Rat} \mathrm{SCH}$ expressing human OATP1B3-is a novel in vitro model allowing simultaneous assessment of hepatic uptake, hepatocellular accumulation and biliary excretion process of a human OATP1B3 substrate. This model could be a potential tool for screening for livertargeting compounds mediated by OATP1B3.
\end{abstract}

\section{INTRODUCTION}

Organic Anion Transporting Peptide (OATP) 1B3 is a member of the solute carrier organic anion (SLCO) transporter superfamily. OATP1B3 is localized to the basolateral membrane of human hepatocytes and has $\sim 80 \%$ amino acid homology with another basolateral transport protein, OATP1B1 (1). Under normal physiological conditions, both OATP1B1 and OATP1B3 specifically express in the human liver (2). They can transport many clinically important drugs, including widely prescribed lipidlowering statins, anti-diabetic, antibiotics, and anticancer agents, from blood into the liver (3). Tissue targeting of therapeutic molecules mediated by transporters, including liver targeting via liverspecific OATP1B1 and OATP1B3, is an emerging area in drug development (4-6). There is a need to develop a screening tool that can simultaneously assess OATP1B3-mediated hepatic uptake and hepatocellular accumulation of drug candidates in vitro.

Hepatocytes cultured in a sandwich configuration between two layers of extracellular matrix exhibit proper localization of basolateral and canalicular transport proteins and functional metabolic activity (7). The $\mathrm{SCH}$ system is a physiologically relevant and well characterized in vitro model with which to evaluate hepatic uptake, hepatocellular accumulation, and biliary excretion of 
drugs and derived metabolites (7). It is a valuable tool used in drug discovery and development to characterize in vitro hepatobiliary disposition of many drugs. SCH has been established successfully using primary hepatocytes for humans $(8-11)$ and preclinical species, including rats $(12,13)$. Due to the lack of rodent ortholog of OATP1B1 and OATP1B3, currently, there is no rodent $\mathrm{SCH}$ model available to study hepatobiliary disposition of human OATP1B1 and OATP1B3 substrates in vitro. The current study was designed to develop a novel rat $\mathrm{SCH}$ model that expresses human OATP1B3 and to utilize this model to assess the hepatic disposition of human OATP1B3 substrates. Such a model would allow simultaneous detection of OATP1B3-mediated hepatic uptake and hepatocellular accumulation of OATP1B3 substrate.

Adenoviral vector has been successfully used in gene expression in primary rat $(7,14)$ and human hepatocytes (15). In the current studies, human OATP1B3 was expressed in rat SCH by adenoviral vector-mediated gene transfer. OATP1B3-mediated hepatic uptake in rat $\mathrm{SCH}$ was assessed using cholecystokinin 8 (CCK-8), a specific substrate of OATP1B3 (16), as the probe substrate. Taurocholate (TC) is subject to extensive hepatic biliary excretion in rat $\mathrm{SCH}$ and has been routinely used as a model substrate to assess the function of bile canaliculi in $\mathrm{SCH}$ (7). In rat hepatocytes, uptake of TC into hepatocytes is primarily mediated by basolateral transport protein $\mathrm{Na}^{+}$-taurocholate co-transporting polypeptide (Ntcp) (17), while biliary excretion of TC is mediated by the bile salt export pump (BSEP) (18). TC is also a substrate of OATP1B3 (19). TC was used as a model substrate in the current study to assess the hepatobiliary disposition of substances in rat $\mathrm{SCH}$ when OATP1B3 is overexpressed.

\section{MATERIALS AND METHODS}

\section{Chemicals}

$\left[{ }^{3} \mathrm{H}\right]-\mathrm{CCK}-8$ (specific activity $88.0 \mathrm{Ci} / \mathrm{mmol}$ ) and $\left[{ }^{3} \mathrm{H}\right]-\mathrm{TC}$ (specific activity $5.0 \mathrm{Ci} / \mathrm{mmol}$ ) was purchased from Perkin Elmer Life Science (Waltham, MA). Unlabeled CCK-8, Triton X-100, dimethyl sulfoxide (DMSO), and Hank's Balanced Salt Solution (HBSS) were purchased from SigmaAldrich (St. Louis, MO). Fetal bovine serum (FBS) was purchased from Hyclone Laboratories (Logan, Utah). Matrigel $^{\mathrm{TM}}$, BioCoat ${ }^{\mathrm{TM}}$ plates, and insulin/transferrin/selenium $\left(\mathrm{ITS}^{+}\right.$) were purchased from BD Biosciences (Bedford, MA). Bio-Safe II liquid scintillation mixture was purchased from Research Products International (Mt. Prospect, IL).
All other materials were purchased from VWR or Thermo Fisher Scientific (Waltham, MA).

\section{Adenoviral Vectors}

The adenoviral vector Ad-OATP1B3, which expresses FLAG-tagged OATP1B3, and control adenoviral vector (Ad-LacZ), which expresses $\beta$ galactosidase (lacZ), were published previously (15). The titer of adenoviral vectors was determined using the Adeno-X Rapid Titer Kit (Clontech Laboratories, Mountain View, CA).

\section{Sandwich-culture hepatocytes (SCH) and transduction of adenoviral vectors}

Male Wistar rat hepatocytes in suspension, which were isolated by the collagenase perfusion method (20), were purchased from Triangle Research Laboratories (Research Triangle Park, NC). After centrifugation of the cell suspension at $4{ }^{\circ} \mathrm{C}$ at $76 \mathrm{~g}$ for $6 \mathrm{~min}$ and decanting the shipping medium, cells were resuspended in fresh seeding medium and had viability of greater than $81 \%$ (average $85 \%$, ranging $81-93 \%)$. Hepatocytes were then cultured in sandwich configuration as published previously (7, 14, 21). Briefly, cells were seeded onto 24-well BioCoat ${ }^{\mathrm{TM}}$ culture plates at $2.5 \times 10^{5}$ cells per well (BD Bioscience) with seeding medium (phenol redfree Dulbecco's modified Eagle's medium [DMEM] supplemented with nonessential amino acids, 5\% fetal bovine serum, L-glutamine, penicillin/streptomycin, $4 \mu \mathrm{g} / \mathrm{mL}$ insulin, and $1 \mu \mathrm{M}$ dexamethasone) and incubated at $37{ }^{\circ} \mathrm{C}$ in a humidified incubator with $95 \%$ air $/ 5 \% \mathrm{CO}_{2}$. One hour after seeding, seeding medium was replaced with fresh seeding medium without adenoviral vectors (non-transduced) or with $\mathrm{Ad}-\mathrm{LacZ}$ or AdOATP1B3 at a multiplicity of infection (MOI) of 5. Approximately $24 \mathrm{~h}$ after seeding, cells were overlaid with Matrigel $^{\mathrm{TM}}$ at $0.25 \mathrm{mg} / \mathrm{mL}$ in feeding medium containing $0.1 \mu \mathrm{M}$ dexamethasone and ITS+ premix (feeding medium); the feeding medium was then changed every $24 \mathrm{~h}$ until the day of experiment.

\section{Transport Studies in rat SCH}

$\left[{ }^{3} \mathrm{H}\right]-\mathrm{CCK}-8$ accumulation in rat $\mathrm{SCH}$ was determined in protein-free standard HBSS buffer containing $\mathrm{Ca}^{2+}$, similar to that published previously (22). The substrate concentration of CCK-8 $(1 \mu \mathrm{M})$ was below the $K_{\mathrm{m}}$ values of CCK- 8 transport by OATP1B3 $(3.82 \mu \mathrm{M})(23)$ and that of CCK-8 uptake in primary rat hepatocyte $(6.7 \mu \mathrm{M})$ (16). Initial uptake of CCK-8 in non-transduced rat hepatocytes was linear over at least 1 min (16). Incubation of 
$\left[{ }^{3} \mathrm{H}\right]-\mathrm{CCK}-8(1 \mu \mathrm{M})$ was determined at $20 \mathrm{sec}$, which was in the linear range of both non-transduced (16) and Ad-OATP1B3-transduced rat $\mathrm{SCH}$ determined in the current study. At the end of substrate incubation, $\mathrm{SCH}$ was washed three times with icecold standard HBSS buffer. Cells were then lysed on ice with $0.2 \mathrm{~mL}$ of ice-cold $0.5 \%$ Triton-X 100 in phosphate buffered saline (PBS). $\quad\left[{ }^{3} \mathrm{H}\right]-\mathrm{CCK}-8$ accumulation was determined by liquid scintillation spectrometry (LS6500 scintillation counter, Beckman Coulter, Brea, CA). Uptake studies were also conducted in blank BioCoat ${ }^{\mathrm{TM}}$ plates overlaid with Matrigel without hepatocytes to correct for nonspecific binding. BCA assay (Pierce Chemical, Rockford, IL) was performed to normalize substrate accumulation to the protein concentrations.

TC accumulation in rat $\mathrm{SCH}$ was determined similar to the method previously described (14). Rat $\mathrm{SCH}$ were rinsed twice with standard HBSS and then incubated in $\mathrm{Ca}^{2+}$-free $\mathrm{HBSS}$ (to disrupt the canalicular networks by opening the tight junctions) or standard HBSS for $10 \mathrm{~min}$ at $37^{\circ} \mathrm{C}$. Cells were then incubated for $10 \mathrm{~min}$ at $37^{\circ} \mathrm{C}$ in standard HBSS containing $\left[{ }^{3} \mathrm{H}\right]-\mathrm{TC}(1 \mu \mathrm{M}, 100 \mathrm{nCi})$. At the end of the incubation, cells were rinsed three times with icecold standard HBSS buffer and solubilized in icecold phosphate buffered saline (PBS) containing $0.5 \%$ Triton-X-100. TC biliary excretion was determined by subtracting TC accumulation in cells (rat $\mathrm{SCH}$ preincubated in $\mathrm{Ca}^{2+}$-free $\mathrm{HBSS}$ ) from that in cells + bile canaliculi (BC) (rat SCH preincubated in standard HBSS). Substrate accumulation was determined similarly to that described above by liquid scintillation counting, normalized by protein concentration. TC uptake in a blank BioCoat ${ }^{\mathrm{TM}}$ plates overlaid with Matrigel without cells was conducted to correct for nonspecific binding.

The biliary excretion index (BEI; \%) and in vitro biliary clearance $\left(\mathrm{Cl}_{\text {biliary }}\right)(\mathrm{ml} / \mathrm{min} / \mathrm{kg})$ of $\mathrm{TC}$ were determined in rat SCH using B-CLEAR ${ }^{\circledR}$ technology (U.S. Pat. No. 6,780,580, Pat. No. 7,604,934) (24) (Qualyst Transporter Solutions, BioIVT, Durham, NC) according to the following equations (12):

Equation 1:

$$
B E I=\frac{\text { Accumulation }_{\text {cell }+B C}-\text { Accumulation }_{\text {cells }}}{\text { Accumulation }_{\text {cells }+B C}} X 100 \%
$$

Equation 2:

$$
\text { In vitro } C l_{\text {biliary }}=\frac{\text { Accumulation }_{\text {cells }+B C-} \text { Accumulation }_{\text {cells }}}{A U C_{\text {medium }}}
$$

$\mathrm{AUC}_{\text {medium }}$ was the product of the medium concentration and the incubation time (10 min). The medium concentration of TC was defined as the initial TC concentration $(1 \mu \mathrm{M})$ as the medium concentrations at the end of the incubation did not differ by more than $10 \%$ compared with that at the beginning. The in vitro $\mathrm{Cl}_{\text {biliary }}(\mathrm{ml} / \mathrm{min} / \mathrm{mg}$ protein) was scaled to kilogram of body weight, assuming 40 $\mathrm{g}$ of rat liver tissue $/ \mathrm{kg}$ of body weight and $200 \mathrm{mg}$ protein/g of rat liver tissue (25).

\section{Immunoblotting}

After washing once with standard HBSS buffer, $\mathrm{SCH}$ were lysed in lysis buffer containing $1 \mathrm{mM}$ EDTA, $1 \%$ SDS, and Complete cocktail (Roche Diagnostics, Mannheim, Germany). BCA assay (Pierce, Rockford, IL) was conducted to determine protein concentrations. Proteins from whole-cell lysates (50 $\mu \mathrm{g})$ separated by sodium dodecyl sulphatepolyacrylamide gel electrophoresis using $10 \%$ gel (Biorad, Hercules, CA). After transferring proteins to nitrocellulose membranes, blocking in $5 \%(\mathrm{w} / \mathrm{v})$ milk in Tris-buffered saline containing Tween 20 (TBST), the blots were probed with mouse monoclonal antibodies against FLAG and $\beta$-Actin (Sigma-Aldrich, St. Louis, MO), followed by incubation with an HRP-conjugated anti-mouse secondary antibody after washing. Immunoblotting signals were detected by a Bio-Rad ChemiDoc XRS imaging using chemiluminescent substrate Supersignal West Duro (Pierce, Rockford, IL).

\section{Immunofluorescent Staining}

Immunofluorescent staining was conducted similarly to that published previously $(26,27)$. In brief, rat hepatocytes were grown on rat collagen-coated coverslip. Subsequent transduction with adenoviral vectors and sandwich-culture was the same as described above. After rinsing once with PBS buffer, cells were subjected to fixation with ice-cold $100 \%$ methanol for $15 \mathrm{~min}$, permeabilization with $0.25 \%$ Triton X-100 in PBS for $10 \mathrm{~min}$ at room temperature and blocking with 5\% (w/v) BSA in PBS for $1 \mathrm{~h}$ at room temperature. For immunofluorescence staining of FLAG-tagged OATP1B3, cells were then coincubated with the mouse monoclonal anti-FLAG antibody (Sigma-Aldrich, St. Louis, MO, 1:100 dilution in PBS containing $5 \%(\mathrm{w} / \mathrm{v}) \mathrm{BSA}$ ) at $37{ }^{\circ} \mathrm{C}$ for $2 \mathrm{~h}$. Following three washes with PBS, cells were then co-incubated with an Alexa Fluor 488conjugated goat anti-mouse IgG (Life Technologies, Grand Island, NY, 1:200 dilution in PBS containing $5 \%(\mathrm{w} / \mathrm{v}) \mathrm{BSA}$ ) at $37{ }^{\circ} \mathrm{C}$ for $1 \mathrm{~h}$. Cells were also 
incubated for $5 \mathrm{~min}$ in $300 \mathrm{nM} \mathrm{4',6-diamidino-2-}$ phenylindole (DAPI) to counterstain nuclei. After washing off DAPI, the coverslips were mounted on glass slides with ProLong gold antifade reagent (Life Technologies, Grand Island, NY). Images were captured using a Olympus XL73 inverted fluorescence microscope system with 10X and 20X objectives (Olympus Scientific Solutions Americas Corp., Waltham, MA).

\section{Lactate Dehydrogenase (LDH) Cytotoxicity Assay}

Assays were conducted similarly to those published previously $(21,22)$ using a lactate dehydrogenase (LDH) cytotoxicity detection kit (Roche Diagnostics, Mannheim, Germany). Untreated and Triton-X (2\%)-treated cells served as the negative control and $100 \%$ cytotoxicity positive control, respectively.

\section{Statistical Analysis}

As indicated in the figure legend, substrate accumulation and associated standard errors (SEs) were estimated by linear mixed models; fold changes in substrate accumulation and associated SEs were estimated by generalized linear mixed models (GLMM). Models incorporate a fixed effect (treatment group), and random effects (culture day), adjusting for group-specific overdispersion (in GLMM). In the case of multiple comparisons, we reported $p$-values after Bonferroni correction. A twosided $p$-value of $<0.05$ defines statistical significance. Paired $t$-test was utilized to determine the statistical difference in $\mathrm{BEI}$ and in vitro $\mathrm{Cl}_{\text {biliary }}$. SAS software (version 9.4, Cary, NC) was utilized for statistical analysis.

\section{RESULTS}

\section{Expression of OATP1B3 in Ad-OATP1B3- transduced SCH}

As shown in Figure. 1A, adenoviral vector-mediated expression of OATP1B3 increased over days in culture with strong immunoblot signal detected on day 4 of culture. Immunoblot with FLAG antibody did not detect OATP1B3 expression in nontransduced cells (day 0). FLAG immunofluorescent staining showed primarily plasma membrane localization of FLAG-tagged human OATP1B3 in Ad-OATP1B3-transduced rat SCH (Figure. 1B). No staining of FLAG-OATP1B3 was detected in nontransduced control cells (Figure S1)
A

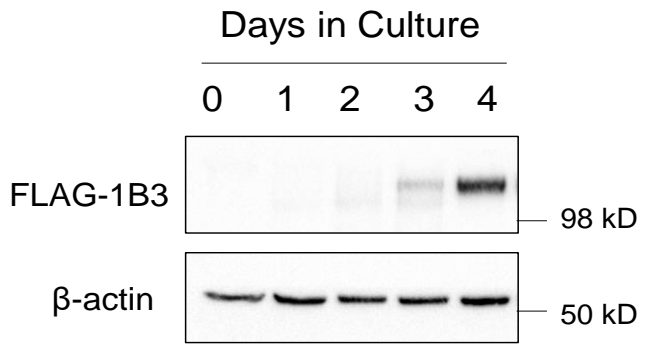

B
Ad-1B3 MOI $560 X$

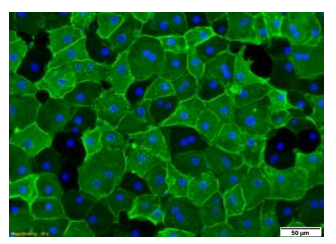

Ad-1B3 MOI 5 20X

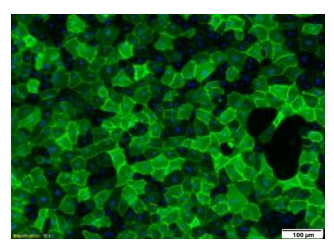

Figure 1. Adenoviral vector-mediated expression of human OATP1B3 in rat SCH. Primary rat hepatocytes were transduced with Ad-OATP1B3 at MOI of 5 and cultured in sandwich configuration. (A) Immunoblot of FLAG and $\beta$-actin in non-transduced (day 0) and AdOATP1B3-transduced rat SCH cultured for the indicated days. Representative images from one experiment of a total of four independent experiments ( $N=4$ rat livers) are shown. (B) Immunofluorescence staining with FLAG antibody in Ad-OATP1B3-transduced rat SCH at day 4 of culture. Representative images in hepatocytes from $N=3$ rat livers are shown. Images were captured using Olympus XL73 inverted fluorescence microscope system using 10X and 20X objectives. Scale bars showed $50 \mu \mathrm{M}$ and $100 \mu \mathrm{M}$ in the left and right panel, respectively.

\section{Linear uptake range of $\left[{ }^{3} \mathrm{H}\right]-\mathrm{CCK}-8$ in Ad- OATP1B3-transduced rat SCH}

The time-dependent total accumulation of $\left[{ }^{3} \mathrm{H}\right]-$ CCK-8 was characterized in rat $\mathrm{SCH}$ with and without Ad-OATP1B3 transduction on day 4 of culture. As shown in Figure 2, OATP1B3-mediated $\left[{ }^{3} \mathrm{H}\right]-\mathrm{CCK}-8(1 \mu \mathrm{M})$ accumulation in Ad-OATP1B3transduced cells was linear at least up to $5 \mathrm{~min}$.

Total accumulation of $\left[{ }^{3} \mathrm{H}\right]-\mathrm{CCK}-8$ in rat $\mathrm{SCH}$ with and without Ad-OATP1B3 transduction

In non-transduced rat $\mathrm{SCH}$, total accumulation of $\left[{ }^{3} \mathrm{H}\right]-\mathrm{CCK}-8$ in cells+BC at day 4 of culture was significantly reduced to $0.26 \pm 0.06$ fold of that at day 0 of culture $(p<0.001)$ (Figure $3 \mathrm{~A})$. These data suggest that day $4 \mathrm{SCH}$ has minimal CCK-8 uptake mediated by endogenous rat $\mathrm{SCH}$ transporter

On day 4 of culture, total accumulation of $\left[{ }^{3} \mathrm{H}\right]-$ CCK-8 in Ad-OATP1B3-transduced $\mathrm{SCH}$ was 
significantly greater than that in the non-transduced or Ad-LacZ-transduced $\mathrm{SCH}$; there was no statistically significant difference in total $\left[{ }^{3} \mathrm{H}\right]-\mathrm{CCK}$ 8 accumulation between non-transduced and AdLacZ-transduced cells (Figure 3B). LDH assay results showed no cytotoxicity in Ad-OATP1B3transduced cells (supplemental Figure S2). Taken together, the findings suggest that day 4 of culture has efficient OATP1B3-mediated transport.

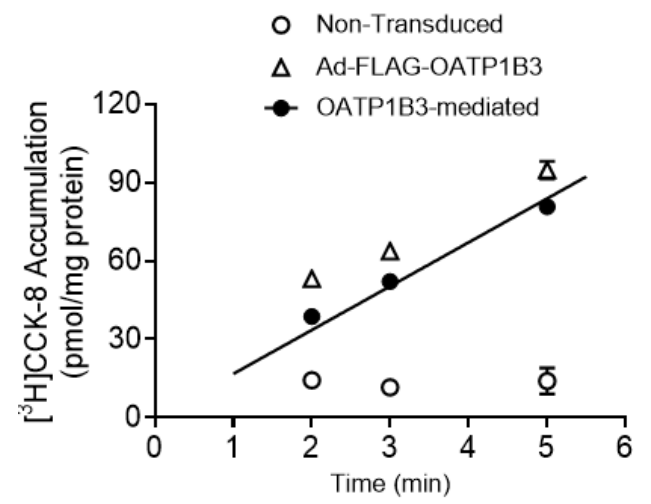

Figure 2. Time-dependent accumulation of $\left[{ }^{3} \mathrm{H}\right]-\mathrm{CCK}-8$ $(1 \mu \mathrm{M})$ cells+BC of rat SCH. Accumulation of $\left[{ }^{3} \mathrm{H}\right]-\mathrm{CCK}-$ $8(1 \mu \mathrm{M})$ was determined in standard HBSS buffer (with $\mathrm{Ca}^{2+}$ ) on day 4 culture of non-transduced (open circles) and Ad-OATP1B3-transduced (MOI=5) (open triangles) rat $\mathrm{SCH}$ for 2, 3, and 5 min. For non-transduced and AdOATP1B3-transduced cells, data were expressed as mean $\pm S D$ from $N=1$ experiment in triplicate. Error bars were in visible when overlapping with the symbols. OATP1B3mediated $\left[{ }^{3} \mathrm{H}\right]-\mathrm{CCK}-8$ accumulation (closed circles) was determined by subtracting the mean value in nontransduced (open circles) from that in Ad-OATP1B3transduced (open triangles) $\mathrm{SCH}$. Line represents the linear regression of the OATP1B3-mediated CCK-8 transport.

\section{TC disposition in rat $\mathrm{SCH}$ with and without Ad- OATP1B3 transduction}

As shown in Figure 4, compared with nontransduced $\mathrm{SCH}$, expressing OATP1B3 in rat $\mathrm{SCH}$ significantly increased total accumulation of $\left[{ }^{3} \mathrm{H}\right]-\mathrm{TC}$ in cells+bile $(39.3 \pm 5.1$ vs. $25.4 \pm 5.1 \mathrm{pmol} / \mathrm{mg}$ protein, Ad-OATP1B3 vs. none, $p=0.001$ ), consistent with the fact that TC is a substrate of OATP1B3 (19). Over-expressing OATP1B3 in rat $\mathrm{SCH}$ also significantly increased accumulation of $\left[{ }^{3} \mathrm{H}\right]$-TC in cells $(11.5 \pm 4.4$ vs. $4.16 \pm 4.8 \mathrm{pmol} / \mathrm{mg}$ protein) (Figure 4). There was no significant difference in $\mathrm{TC}$ BEI or in vitro $\mathrm{Cl}_{\text {biliary }}$ values between rat SCH with and without Ad-OATP1B3transduction.
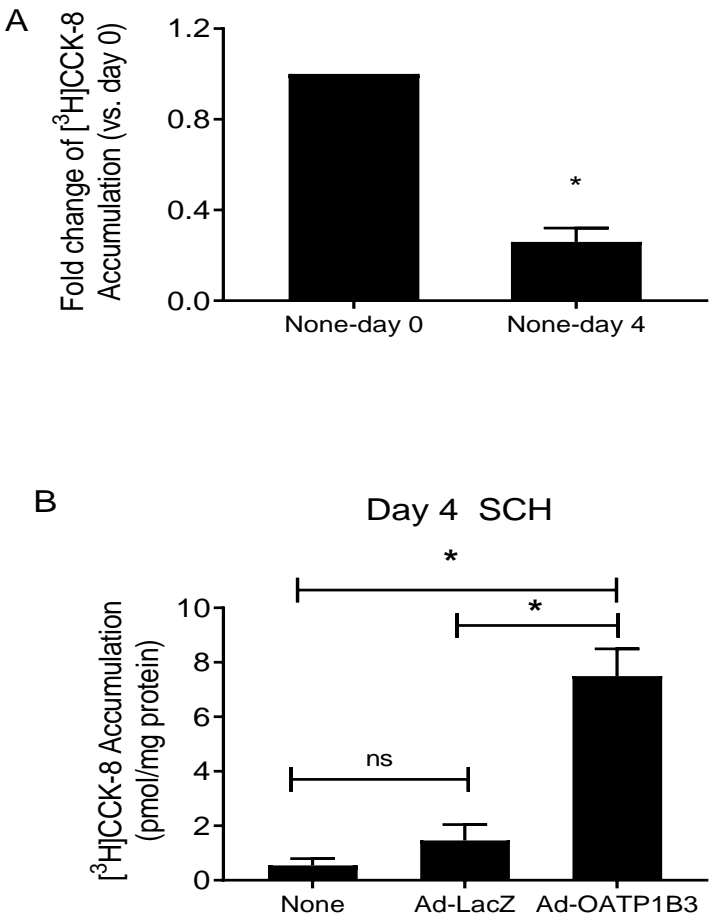

Figure 3. Comparison of $\left[{ }^{3} \mathrm{H}\right]-\mathrm{CCK}-8$ accumulation in conditions of different culture day and Ad-OATP1B3transduction. $\left[{ }^{3} \mathrm{H}\right]$-CCK-8 accumulation $(1 \mu \mathrm{M}, 20 \mathrm{sec})$ in $\mathrm{HBSS}+\mathrm{Ca}^{2+}$ buffer was determined in non-transduced (None) rat SCH on day 0 and day 4 (A), and in Ad-LacZor Ad-OATP1B3-transduced rat SCH on day 4 (B). (A) Model estimated fold change and associated SE of $\left[{ }^{3} \mathrm{H}\right]-$ CCK-8 accumulation on day 4 vs. day 0 non-transduced $\mathrm{SCH}$. A generalized linear mixed effect model was utilized to analyze the data. *, $p<0.05$ vs. non-transduced (none) control. (B) Model estimated $\left[{ }^{3} \mathrm{H}\right]-\mathrm{CCK}-8$ accumulation and associated SE in non-transduced, AdLacZ- and Ad-OATP1B3-transduced day 4 rat SCH. A linear mixed effect model was utilized to analyze the data. $*, p<0.05$ vs. indicated control. ns, $p>0.05$ vs. indicated control. Experiments were conducted in triplicate using hepatocytes from $N=3$ or 4 rat livers. Data are represented as model estimated mean values and associated standard error (SE). Data from non-transduced day $4 \mathrm{SCH}$ in (A) were replotted in $\mathrm{B}$ for comparison purposes.

\section{DISCUSSION}

The current study developed a novel rat $\mathrm{SCH}$ model expressing human OATP1B3. In rat hepatocytes, it has been reported that Oatp1b2 is the endogenous basolateral transport protein that mediates hepatic uptake of CCK-8 and that mRNA of Oatp1b2 in rat SCH was reduced more than 10fold on day 4 compared with day 0 (28). The negligible $\left[{ }^{3} \mathrm{H}\right]-\mathrm{CCK}-8$ uptake mediated by endogenous rat transporter in non-transduced day 4 
SCH (Figure 3A) is consistent with reduced Oatp1b2 expression over days in culture in rat hepatocytes reported previously (28). In the current study, in AdOATP1B3-transduced SCH at day 4 of culture, there was extensive expression of OATP1B3 protein (Figure 1) and effective OATP1B3-mediated uptake of CCK-8 into hepatocytes (Figure 3). In addition, the TC BEI in Ad-OATP1B3-transduced SCH was similar to non-transduced cells without detected toxicity (Figure S2). Day 4 cultured non-transduced rat $\mathrm{SCH}$ has been demonstrated to be an optimal culture time to study in vitro drug biliary disposition, as day 4 is when extensive bile canaliculi are formed (11-13). Our data suggest that Ad-OATP1B3transduced rat $\mathrm{SCH}$ can also be used to assess hepatic biliary disposition of OATP1B3 substrates at day 4 of culture.

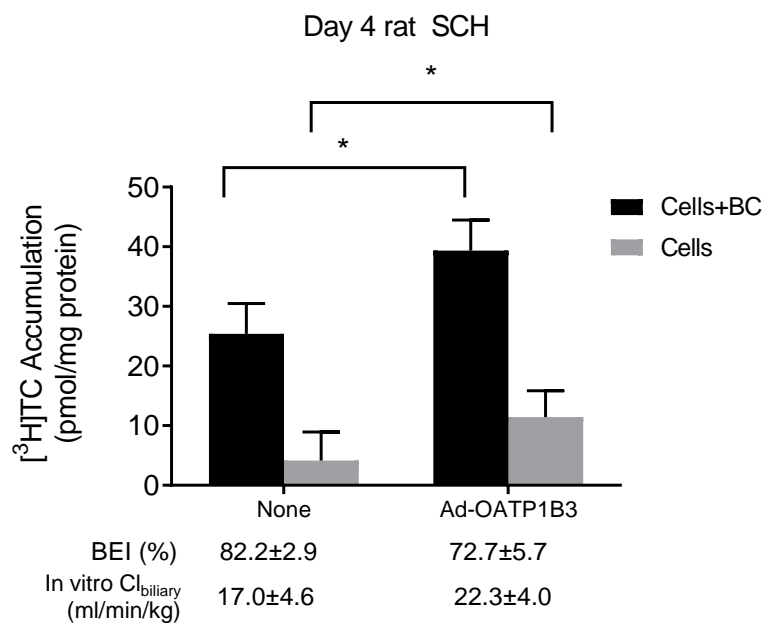

Figure 4. TC accumulation in cells+BC and cells after 10incubation with $1 \mu \mathrm{M}$ TC in non-transduced (none) and Ad-OATP1B3-transduced day 4 rat SCH. Model estimated $\left[{ }^{3} \mathrm{H}\right]-\mathrm{TC}$ accumulation $(1 \mu \mathrm{M}, 10 \mathrm{~min})$ and associated SE in cells+BC (closed bars) and cells (open bars). A linear mixed effect model was utilized to analyze the data. $\mathrm{BEI}$ and in vitro $\mathrm{Cl}_{\text {biliary }}$ values are expressed as mean \pm standard error of mean (SEM). Experiments were conducted in triplicate using hepatocytes from $N=4$ rat livers. *, indicates a statistically significant difference $(p<0.05)$ vs. none.

The hepatobiliary elimination process of TC involves basolateral uptake and efflux, and biliary excretion (10). TC disposition in human $\mathrm{SCH}$ was described by a pharmacokinetic model in a previous publication (10). The model simulation showed that while both TC total concentration in cells and total amount of TC in Cells+bile was sensitive to changes in $\mathrm{Cl}_{\text {uptake }}$ of TC (10), BEI and total amount of TC in bile were not sensitive to changes in $\mathrm{Cl}_{\text {uptake }}$ (10). In the current study, increased hepatic uptake of $\left[{ }^{3} \mathrm{H}\right]-$ $\mathrm{TC}$ in OATP1B3-expressing rat $\mathrm{SCH}$ led to a significant increase in total accumulation of $\left[{ }^{3} \mathrm{H}\right]-\mathrm{TC}$ in cells+bile and cells without affecting in vitro $\mathrm{CL}_{\text {biliary. }}$ Our data are consistent with the predicted trend of in vitro disposition of TC in human $\mathrm{SCH}$ upon changes in $\mathrm{CL}_{\text {uptake, suggesting that } \mathrm{TC}}$ disposition in this OATP1B3-expressing rat $\mathrm{SCH}$ may be similar to that in human $\mathrm{SCH}$.

Transporter-overexpressing mammalian stable cell lines, including human embryonic kidney (HEK) 293 and Chinese Hamster Ovary (CHO) cells (21, 29-32), have been extensively utilized to study OATP1B1- and OATP1B3-mediated transport. These cell culture models are suitable to determine substrates of transporters, characterize transport kinetics, and assess inhibition potency of transporter inhibitors. Suspension hepatocytes are gold-standard to determine substance initial total accumulation. Application of the B-CLEAR ${ }^{\circledR}$ technology in AdOATP1B3-expressing rat $\mathrm{SCH}$ allows simultaneous determination of not only total substrate accumulation (cells+bile), but also hepatocellular accumulation (cells) and in vitro biliary excretion of the compound in the presence of OATP1B3.

We and others also reported that OATP1B3 mRNA and immunoreactivity is detected in various cancers $(33,34)$, however, the exact function of OATP1B3 in cancers remains to be elucidated. Because OATP1B1 and OATP1B3 are abundantly and primarily expressed in human liver $(2,35)$, they provide opportunities for liver-targeted drug design. Some therapeutic agents exert their pharmacological action via extensive uptake by the liver include 3hydroxy-3-methyl-glutaryl coenzyme-A (HMG$\mathrm{CoA})$ reductases inhibitor statins, glucokinase activators (GKA) (36), and stearoyl-CoA desaturase1 (SCD1) inhibitors (37). Statin can accumulate in the muscle and has potential to cause statin-induced myopathy when systemic exposure of statin increases due to drug-drug interactions $(38,39)$. Statins are substrates of hepatic OATPs $(23,40)$. The liver-targeting feature of statins is beneficial for their clinic tolerability against statin-induced myopathy. A liver-selective GKA with a liver-to-pancreas ratio greater than 50-fold reduces the risk of insulin overproduction due to excessive GK activation in pancreas $(36,41)$. A liver-targeting SCD1 inhibitor, which has $>10$-fold liver-to-plasma ratio and $>30$ fold liver-to-skin ratio, did not elicit adverse responses found in a systemically distributed SCD1 inhibitor, including severe hair loss and skin and eye abnormalities (37). Hence, the Ad-OATP1B3- 
expressing rat $\mathrm{SCH}$ could be a useful model to use when screening for liver-targeting compounds during drug development. This approach can potentially be extended to other liver-specific hepatic transporters, such as OATP1B1.

\section{CONCLUSION}

In conclusion, the current study established a novel human OATP1B3-expressing rat SCH model that can be used to study hepatobiliary disposition of OATP1B3 substrates. This model has been successfully utilized to assess hepatic uptake of OATP1B3 substrate CCK-8 and hepatobiliary disposition of TC in current studies. Further studies are warranted to test the application of this model using liver-targeting drugs that are OATP substrates.

Acknowledgements. This research was supported by NIH R01 GM094268 (W. Y.). The content is solely the responsibility of the authors and does not necessarily represent the official views of the National Institutes of Health. Research reported in this publication was supported in part by the National Cancer Institute Cancer Center Support Grant (CCSG) P30-CA225520 awarded to the University of Oklahoma Stephenson Cancer Center and used the Biostatistics and Research Design of the CCSG Shared Resources. The SCH studies using BCLEAR $^{\circledR}$ technology were conducted under a research agreement between OUHSC and Qualyst Transporter Solutions, LLC (Durham, NC).

Authorship Contributions. Participated in research design: TF, WY; Conducted experiments: TF, WY; Performed data analysis: TF, CX, WY; Wrote or contributed to writing the manuscript: $\mathrm{TF}, \mathrm{CX}$ and WY

\section{REFERENCES}

1. König J, Cui Y, Nies AT, Keppler D. Localization and genomic organization of a new hepatocellular organic anion transporting polypeptide. J Biol Chem. 2000;275(30):23161-23168.

2. König J, Cui Y, Nies AT, Keppler D. A novel human organic anion transporting polypeptide localized to the basolateral hepatocyte membrane. Am J Physiol Gastrointest Liver Physiol. 2000;278(1):G156-164.
3. König J. Uptake transporters of the human OATP family: molecular characteristics, substrates, their role in drug-drug interactions, and functional consequences of polymorphisms. Handb Exp Pharmacol. 2011(201):1-28.

4. Tu M, Mathiowetz AM, Pfefferkorn JA, Cameron KO, Dow RL, Litchfield J, Di L, Feng B, Liras S. Medicinal chemistry design principles for liver targeting through OATP transporters. Curr Top Med Chem. 2013;13(7):857-866.

5. Zhou J, Xu J, Huang Z, Wang M. Transportermediated tissue targeting of therapeutic molecules in drug discovery. Bioorg Med Chem Lett. 2015;25(5):993-997.

6. Kotsampasakou E, Ecker G. Organic Anion Transporting Polypeptides as Drug Targets. In: Ecker G, Clausen RP, Sitte HH, editors. Transporters as Drug Targets. Weinheim, Germany: Wiley-VCH; 2017.

7. Swift B, Pfeifer ND, Brouwer KL. Sandwichcultured hepatocytes: an in vitro model to evaluate hepatobiliary transporter-based drug interactions and hepatotoxicity. Drug Metab Rev. 2010.

8. Guo C, Brouwer KR, Stewart PW, Mosley C, Brouwer KLR. Probe Cocktail to Assess Transporter Function in Sandwich-Cultured Human Hepatocytes. J Pharm Pharm Sci. 2019;22(1):567-575.

9. Guo C, LaCerte C, Edwards JE, Brouwer KR, Brouwer KLR. Farnesoid $\mathrm{X}$ Receptor Agonists Obeticholic Acid and Chenodeoxycholic Acid Increase Bile Acid Efflux in Sandwich-Cultured Human Hepatocytes: Functional Evidence and Mechanisms. J Pharmacol Exp Ther. 2018;365(2):413-421.

10. Guo C, Yang K, Brouwer KR, St Claire RL, 3rd, Brouwer KL. Prediction of Altered Bile Acid Disposition Due to Inhibition of Multiple Transporters: An Integrated Approach Using Sandwich-Cultured Hepatocytes, Mechanistic Modeling, and Simulation. J Pharmacol Exp Ther. 2016;358(2):324-333.

11. Lee JK, Marion TL, Abe K, Lim C, Pollock GM, Brouwer KL. Hepatobiliary disposition of troglitazone and metabolites in rat and human sandwich-cultured hepatocytes: use of Monte Carlo simulations to assess the impact of changes in biliary excretion on troglitazone 
sulfate accumulation. J Pharmacol Exp Ther. 2010;332(1):26-34.

12. Liu X, Chism JP, LeCluyse EL, Brouwer KR, Brouwer KLR. Correlation of biliary excretion in sandwich-cultured rat hepatocytes and in vivo in rats. Drug Metab Dispos. 1999;27(6):637-644.

13. Abe K, Bridges AS, Yue W, Brouwer KL. In vitro biliary clearance of angiotensin II receptor blockers and 3-hydroxy-3methylglutaryl-coenzyme A reductase inhibitors in sandwich-cultured rat hepatocytes: comparison with in vivo biliary clearance. J Pharmacol Exp Ther. 2008;326(3):983-990.

14. Yue W, Abe K, Brouwer KL. Knocking down breast cancer resistance protein (Bcrp) by adenoviral vector-mediated RNA interference (RNAi) in sandwich-cultured rat hepatocytes: a novel tool to assess the contribution of Bcrp to drug biliary excretion. Mol Pharm. 2009;6(1):134-143.

15. Powell J, Farasyn T, Kock K, Meng X, Pahwa S, Brouwer KL, Yue W. Novel mechanism of impaired function of organic aniontransporting polypeptide 1B3 in human hepatocytes: post-translational regulation of OATP1B3 by protein kinase $\mathrm{C}$ activation. Drug Metab Dispos. 2014;42(11):1964-1970.

16. Ismair MG, Stieger B, Cattori V, Hagenbuch B, Fried M, Meier PJ, Kullak-Ublick GA. Hepatic uptake of cholecystokinin octapeptide by organic anion-transporting polypeptides OATP4 and OATP8 of rat and human liver. Gastroenterology. 2001;121(5):1185-1190.

17. Kim RB, Leake B, Cvetkovic M, Roden MM, Nadeau J, Walubo A, Wilkinson GR. Modulation by drugs of human hepatic sodium-dependent bile acid transporter (sodium taurocholate cotransporting polypeptide) activity. J Pharmacol Exp Ther. 1999;291(3):1204-1209.

18. Gerloff T, Stieger B, Hagenbuch B, Madon J, Landmann L, Roth J, Hofmann AF, Meier PJ. The Sister of P-glycoprotein Represents the Canalicular Bile Salt Export Pump of Mammalian Liver. Journal of Biological Chemistry. 1998;273(16):10046-10050.

19. Leslie EM, Watkins PB, Kim RB, Brouwer KL. Differential inhibition of rat and human Na+-dependent taurocholate cotransporting polypeptide (NTCP/SLC10A1)by bosentan: a mechanism for species differences in hepatotoxicity. J Pharmacol Exp Ther. 2007;321(3):1170-1178.

20. LeCluyse EL, Audus KL, Hochman JH. Formation of extensive canalicular networks by rat hepatocytes cultured in collagensandwich configuration. Am J Physiol. 1994;266(6 Pt 1):C1764-1774.

21. Pahwa S, Alam K, Crowe A, Farasyn T, Neuhoff S, Hatley O, Ding K, Yue W. Pretreatment With Rifampicin and Tyrosine Kinase Inhibitor Dasatinib Potentiates the Inhibitory Effects Toward OATP1B1- and OATP1B3-Mediated Transport. J Pharm Sci. 2017;106(8):2123-2135.

22. Alam K, Farasyn T, Crowe A, Ding K, Yue W. Treatment with proteasome inhibitor bortezomib decreases organic anion transporting polypeptide (OATP) 1B3mediated transport in a substrate-dependent manner. PLoS One. 2017;12(11):e0186924.

23. Hirano M, Maeda K, Shitara Y, Sugiyama Y. Contribution of OATP2 (OATP1B1) and OATP8 (OATP1B3) to the hepatic uptake of pitavastatin in humans. J Pharmacol Exp Ther. 2004;311(1):139-146.

24. Liu X, LeCluyse EL, Brouwer KR, Lightfoot $\mathrm{RM}$, Lee JI, Brouwer KL. Use of $\mathrm{Ca} 2+$ modulation to evaluate biliary excretion in sandwich-cultured rat hepatocytes. J Pharmacol Exp Ther. 1999;289(3):1592-1599.

25. Seglen PO, Gordon PB. Inhibition of cell spreading by lysosomotropic amines. FEBS Lett. 1979;105(2):345-348.

26. Bow DA, Perry JL, Miller DS, Pritchard JB, Brouwer KL. Localization of P-gp (Abcb1) and Mrp2 (Abcc2) in freshly isolated rat hepatocytes. Drug Metab Dispos. 2008;36(1):198-202.

27. Alam K, Pahwa S, Wang X, Zhang P, Ding K, Abuznait AH, Li L, Yue W. Downregulation of Organic Anion Transporting Polypeptide (OATP) 1B1 Transport Function by Lysosomotropic Drug Chloroquine: Implication in OATP-Mediated Drug-Drug Interactions. Mol Pharm. 2016;13(3):839-851.

28. Tchaparian EH, Houghton JS, Uyeda C, Grillo MP, Jin L. Effect of culture time on the basal expression levels of drug transporters in sandwich-cultured primary rat hepatocytes. Drug Metab Dispos. 2011;39(12):2387-2394.

29. Cui Y, Konig J, Leier I, Buchholz U, Keppler D. Hepatic uptake of bilirubin and its conjugates by the human organic anion 
transporter SLC21A6. J Biol Chem. 2001;276(13):9626-9630.

30. Farasyn T, Crowe A, Hatley O, Neuhoff S, Alam K, Kanyo J, Lam TT, Ding K, Yue W. Preincubation With Everolimus and Sirolimus Reduces Organic Anion-Transporting Polypeptide (OATP)1B1- and 1B3-Mediated Transport Independently of mTOR Kinase Inhibition: Implication in Assessing OATP1B1 - and OATP1B3-Mediated DrugDrug Interactions. J Pharm Sci. 2019;108(10):3443-3456.

31. Gui C, Miao Y, Thompson L, Wahlgren B, Mock M, Stieger B, Hagenbuch B. Effect of pregnane $\mathrm{X}$ receptor ligands on transport mediated by human OATP1B1 and OATP1B3. European Journal of Pharmacology. 2008;584(1):57-65.

32. Izumi S, Nozaki $\mathrm{Y}$, Komori $\mathrm{T}$, Maeda K, Takenaka O, Kusano K, Yoshimura T, Kusuhara H, Sugiyama Y. Substratedependent inhibition of organic anion transporting polypeptide 1B1: comparative analysis with prototypical probe substrates estradiol-17beta-glucuronide, estrone-3sulfate, and sulfobromophthalein. Drug Metab Dispos. 2013;41(10):1859-1866.

33. Alam K, Farasyn T, Ding K, Yue W. Characterization of Liver- and Cancer-typeOrganic Anion Transporting Polypeptide (OATP) 1B3 Messenger RNA Expression in Normal and Cancerous Human Tissues. Drug Metab Lett. 2018.

34. Thakkar N, Kim K, Jang ER, Han S, Kim K, Kim D, Merchant N, Lockhart AC, Lee W. A cancer-specific variant of the SLCO1B3 gene encodes a novel human organic anion transporting polypeptide 1B3 (OATP1B3) localized mainly in the cytoplasm of colon and pancreatic cancer cells. Mol Pharm. 2013;10(1):406-416.

35. König J, Cui Y, Nies AT, Keppler D. Localization and genomic organization of a new hepatocellular organic anion transporting polypeptide. J Biol Chem. 2000;275(30):23161-23168.
36. Pfefferkorn JA, Guzman-Perez A, Litchfield J, Aiello R, Treadway JL, Pettersen J, Minich ML, Filipski KJ, Jones CS, Tu M, Aspnes G, Risley H, Bian J, Stevens BD, Bourassa P, D'Aquila T, Baker L, Barucci N, Robertson AS, Bourbonais F, Derksen DR, Macdougall M, Cabrera O, Chen J, Lapworth AL, Landro JA, Zavadoski WJ, Atkinson K, HaddishBerhane N, Tan B, Yao L, Kosa RE, Varma MV, Feng B, Duignan DB, El-Kattan A, Murdande S, Liu S, Ammirati M, Knafels J, Dasilva-Jardine P, Sweet L, Liras S, Rolph TP. Discovery of (S)-6-(3-cyclopentyl-2-(4(trifluoromethyl)-1H-imidazol-1-

yl)propanamido)nicotini c acid as a hepatoselective glucokinase activator clinical candidate for treating type 2 diabetes mellitus. J Med Chem. 2012;55(3):1318-1333.

37. Powell DA, Black WC, Bleasby K, Chan CC, Deschenes D, Gagnon M, Gordon R, Guay J, Guiral S, Hafey MJ, Huang Z, Isabel E, Leblanc Y, Styhler A, Xu LJ, Zhang L, Oballa RM. Nicotinic acids: liver-targeted SCD inhibitors with preclinical anti-diabetic efficacy. Bioorg Med Chem Lett. 2011;21(24):7281-7286.

38. Mundy G, Garrett R, Harris S, Chan J, Chen D, Rossini G, Boyce B, Zhao M, Gutierrez G. Stimulation of bone formation in vitro and in rodents by statins. Science. 1999;286(5446):1946-1949.

39. Abd TT, Jacobson TA. Statin-induced myopathy: a review and update. Expert Opin Drug Saf. 2011;10(3):373-387.

40. Ho RH, Tirona RG, Leake BF, Glaeser H, Lee W, Lemke CJ, Wang Y, Kim RB. Drug and bile acid transporters in rosuvastatin hepatic uptake: function, expression, and pharmacogenetics. Gastroenterology. 2006;130(6):1793-1806.

41. Pfefferkorn JA. Strategies for the design of hepatoselective glucokinase activators to treat type 2 diabetes. Expert opinion on drug discovery. 2013;8(3):319-330. 